\title{
TRIZ 理论在机械类专业创新能力培养模式构建
}

\author{
单武斌 \\ 湖南电气职业技术学院 \\ DOI:10.32629/er.v3i7.2934
}

\begin{abstract}
[摘 要] 随着我国进入新的发展阶段,产业升级和经济结构调整不断加快,各行各业对技术技能人才的 需求越来越紧迫, 高职学生作为新一代技术创新的主要力量, 如何培养高职学生的创新能力显得至关重 要。文章针对高职学生工程机械类专业技术创新能力现状分析,针对机械设计专业的人才培养方案、教 学设计、考核体系等提出了看法和建议,并通过比赛的促进与激励, 注重学生在学习、设计过程中的实践 性体验, 有效提高人才培养质量与职业岗位能力的匹配度,挖掘学生的创业潜能。
\end{abstract}

[关键词] TRIZ理论; 机械类专业; 创新能力

\section{$1 \mathrm{TRIZ}$ 应用及理论的概述}

如今, 创新已成为制造业的不竭动 力。世界高度重视技术创新, 创新过程不 能完全依靠创新方法是科学思维、科学方 法和科学工具的总称。是技术创新之手段 落, 也是技术创新的内容。1946年,一位前 苏联科学家 (Genrich Achschuler) 创立 了 “问题解决理论-Triz”, 也被称为 “智 慧理论”) 是最具代表性的创新。通过对 人类技术创新———高水平发明专利的 分析, 总结了技术系统的发展历程观规 律, 形成系统的方法论体系, 引导人们创 新解决工程问题。学习、研究、应用和 推广T R IZ理论可以大大减少短技术研 发过程, 提高技术创新水平。

随着我国进入新的发展阶段, 产业升 级和经济结构调整不断加快, 各行各业对 技术技能人才的需求越来越紧迫, 职业教 育重要地位和作用越来越凸显。没有职业 教育现代化就没有教育现代化。可见，高 职院校承担着培养国家技能型人才的历 史重任, 而其中高职学生群体又是技术创 新的主要力量。因此, 如何培养高职学生 的创新能力显得至关重要。

\section{2 高职学生工程机械类专业技} 术创新能力现状分析

现在, 我国高职学生的教育受传统教 学、知识和实践模式的影响, 存在 “强调 技能教学而不是培养创新能力” 的现状, 导致我国高职学生创新能力的普遍偏差。

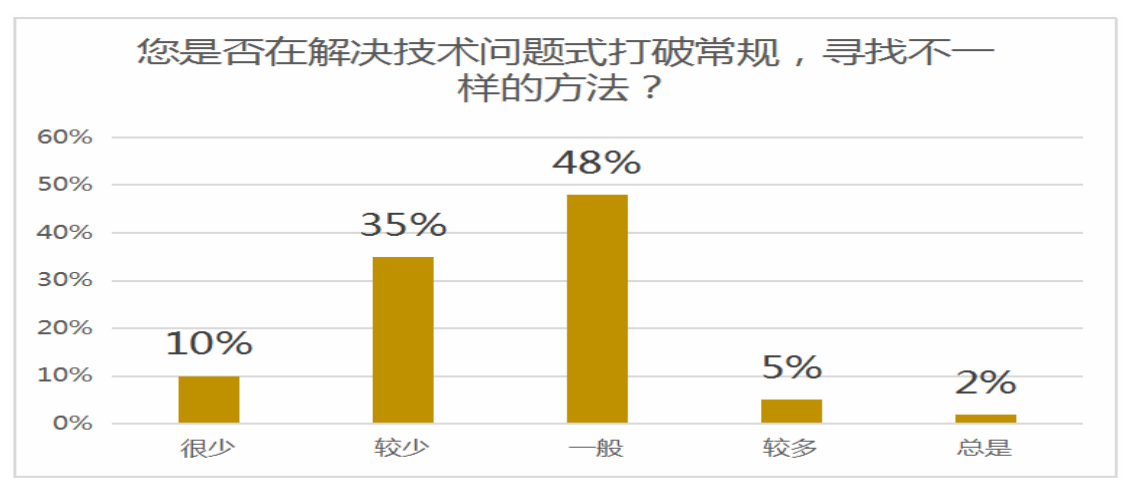

图 1 机械类学生创新意识调研

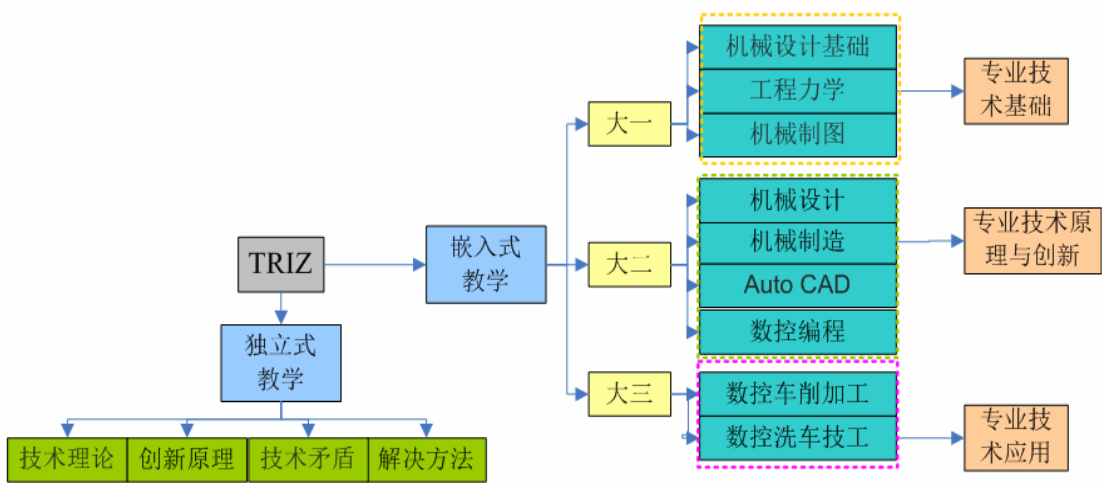

图 2 T R IZ 创新方法引进机械类专业的人才培养方案

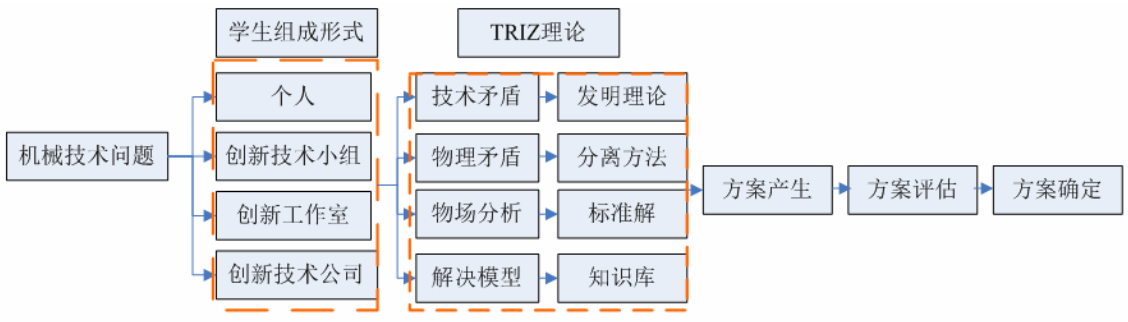

图 3 T R IZ 创新方法引进到工程机械类专业的教学设计中 
课题组曾在 4 个机械类的专业做过 一次调查, 想了解学生在解决技术问题 时是否会打破常规, 45\%的学生承认自己 几乎没有或者很少创新, 48\%的学生习惯 性的选择居中回答 “一般”, 由此可见, 在培养学生的过程中, 很少有学校将 T R IZ创新方法的企业真实案例引入到高职 院校的教育教学当中, 因此, 大多数学生 认为创新能力主要取决于他们的智力和 灵感, 但不知道创新能力是可以培养的, 所以, 为了更好地培养学生的创新能力, 构建了基于TRIZ理论的校企联动创新能 力的培养, 并提出此模式是如何提高学 生创新能力的。

理论教学与实践生产的脱节一直是 高职院校教学中的重要问题之一, 但即 使是注重应用研究的高职院校也注重理 论和简单实践的培养, 但生产线的应用 创新往往是罕见的。假如将T R IZ创新方 法引入学生校企联动双向培养, 则采用 $\mathrm{T}$ R IZ创新方法指导工程技术创新, 解决 生产实践中遇到的技术问题, 以课堂理 论原则补充实际生产经验, 实现学生创 新思维和创新实践的高质量培养。

\section{TRIZ创新方法引进学生培} 养中

3. 1 TRIZ创新方法引进到机械类专 业的人才培养方案中

分解T R IZ创新方法, 引入至专业课 程和课程结构, 形成了以“真实产品为载 体、工作过程导向、真实任务驱动” 的 专业课程体系开发模式, 构建了模块化 课程体系。专业在此基础上优化课程体 系, 机械设计与制造专业与湘潭机电集 团专家合作, 引入TRIZ方法, 构建了 “以 典型产品为载体, 基于工作过程”课程体 系, 校企合作共同开发工学结合项目化 课程。

通过 “真环境、真岗位、真项目”, 构建了TRIZ方法教学循环的 “实战式” 教 学模式, 将课程教学内容项目化、案例化、 模块化, 形成了理实一体的教学课堂。

3.2 TRIZ创新方法引进到工程机械 类专业的教学设计中

对《TRIZ创新理论》课程为例, 如何 应用TRIZ创新方法为例, 如何诊断技术
问题, 如何攻克机械产品当中的技术难 关, 强化TRIZ创新方理论, 推进 “课堂革 命” 积极组织开展教学改革研讨会, 承接 校内外真实加工项目, 教师迅速掌握基 于TRIZ创新理论的问题诊断式教学设计, 植入 “工单式教学”、“任务引领式教学”、 “智慧课堂” 等先进的教学理念, 不断优 化教学设计思路, 提升教学实施能力, 持 续提升教育教学质量, 推动课程教学稳 健有序的改革。

3.3 TRIZ创新方法引进全方位、全 过程的考核方案中

为了实现考核的公平、公正, 项目考 核都实行自评、他评和教师评价三者相 结合。自评实行简易式自评, 他评即根据 教师提前设计的评分标准进行表格式评 价, 教师根据学生的个人和团队参与度、 参与情况进行整体评分, 这样可以减少 教师对学生的主观认知, 增加考核评价 结果的合理性。把是否应用了TRIZ创新 方法作为全程考核的重要指标, 以考评 促学习, 以考核促发展。

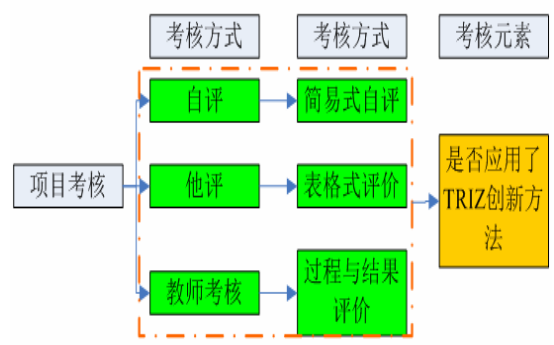

图4 TRIZ创新方法引进到工程机 械类专业的考核方案

3. 4 TRIZ创新方法引进到工程机械 类专业的各类大赛中

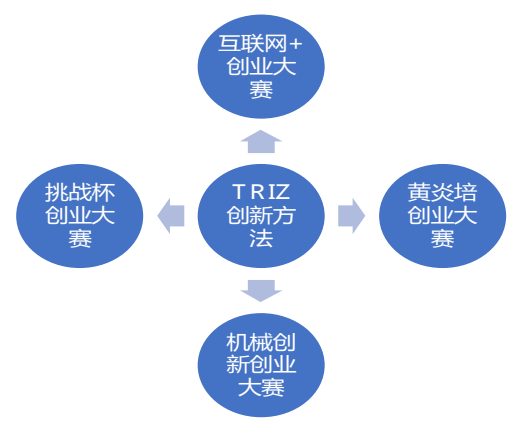

图 5

机电专业大体创新创业大赛有 “机械 创新设计大赛”、“挑战杯”、“黄炎培职业 教育奖创业规划大赛”、“互联网+大学生
创新创业大赛”、“专业技能操作大赛” 以 及 “湖南电气职业技术学院创新创业大 赛”, TRIZ理论与技能竞赛融合, 注重学生 实践能力的培养, 教师和学生都要在专业 课程中形成创新理念、创新意识, 同时注 重学生在学习、设计过程中的实践性体验, 以赛促学, 激发学生的创新意识, 有效提 高人才培养质量与职业岗位能力的匹配 度, 挖掘学生的创业潜能。

\section{4 总结(创新之处)}

(1) 把T R IZ创新方法引进到机械类 专业的人才培养方案, 分解T R IZ创新方 法, 调整专业课程和课程结构, 形成了配 套的专业课程体系。

（2）强化TRIZ创新方理论, 设计基于 TRIZ创新理论的问题诊断式教学模式, 提高问题诊断教学的科学性, 逐步培养 学生创新的思维意识和专业技能。

(3) 把是否应用了 TRIZ创新方法作 为全程考核的重要指标, 以考评促学习; 并实现学生自评、互评、师评三位一体, 过程与结果的双重考核体系。

（4）引进TRIZ创新方法到工程机械 类专业的各类大赛中, TRIZ理论与技能 竞赛融合, 以赛促学, 注重学生实践能力 的培养, 同时注重学生在学习、设计过程 中的实践性体验, 以赛促学, 激发学生的 创新意识。

\section{[参考文献]}

[1]王思梦,邵云飞, 吕剑.互联网 +TRIZ:辅助大学生创新的学习模式研 究 $[\mathrm{J} / \mathrm{OL}$. 电子科技大学学报(社科 版):1-8[2020-07-06].https://doi.org/1 0.14071/j.1008-8105(2019)-4013.

[2]刘华华,许颖.创新思维对人才培养的 作用探析一以3+2中高职衔接数控技术专 业为例[J].湖北农机化,2019,(22):110-111.

[3]Ismail Ekmekci,Emine Elif Nebati. Triz Methodology and Applications[J]. Procedia Computer Science,2019:158.

[4]张世龙, 齐琳。针对TRIZ理论实验 与实践教学的改革研究 [J]. 科技展 望,2014,(15):76。

[5]李明,李大鹏.高校TRIZ创新方法 普及方式研究[J].渤海大学学报(哲学社 会科学版),2019,41(02):134-137. 